\title{
A TRADUÇÃO COMO POLÍTICA LINGUÍSTICA: 0 CASO DA UNASUL
}

\section{TRANSLATION AS LINGUISTIC POLICY: THE CASE OF UNASUR}

\author{
Guilherme Queiroz* \\ Marcos Bagno* \\ Julio C. N. Monteiro***
}

\section{RESUMO}

Busca-se mostrar como a tradução institucional pode ser produto de Políticas Linguísticas, na medida em que estas se configuram, nesse tipo de contexto, também como políticas tradutórias. Estabeleceu-se a União de Nações Sul-Americana (Unasul) como objeto de estudo devido à diversidade de línguas oficiais dessa organização que, em seu próprio Tratado Constitutivo, define o português, o castelhano, o inglês e o neerlandês como idiomas oficiais. Dessa forma, propõe-se uma análise da tradução na Unasul com base na descrição dos processos tradutórios e suas normativas. Parte-se da premissa de que as decisões quanto às linhas de ação dessa instituição, bem como os produtos dela, são acordadas por meio da adoção de um discurso comum e das relações de poder ali presentes. Assim, busca-se fazer uma reflexão sobre a forma como se organizam os interesses dos países nesse âmbito e como isso impacta na produção da tradução do ponto de vista da Política Linguística.

Palavras-chave: política linguística; tradução institucional; Unasul.

\section{ABSTRACT}

This paper seeks to show how institutional translation can be a product of Linguistic Policy, considering that, in this context, these policies could also be featured as translational policies. The Union of South American Nations (UNASUR) was chosen as object of study due to its official languages' diversity, given that in its own Constitutional Treaty Portuguese, Spanish, English and Dutch are defined as official languages. Thus, we analyze the translation in UNASUR, based on the description of the translation procedures and its regulations. Considering the premise that the decisions about the lines of action of this institution, as well as its products, are the result of an agreement between the Member-States, we seek to make a reflection on how the interests of the countries affects the translation production from the point of view of Linguistic Policy.

Keywords: linguistic policy; institutional translation; UNASUR.

\footnotetext{
* Mestre em Estudos da Tradução pela Universidade de Brasília. Brasília (DF), Brasil. guilhermeasq@gmail.com.

** Universidade de Brasília, Brasília (DF), Brasil. bagno.marcos@gmail.com.

*** Universidade de Brasília, Brasília (DF), Brasil. cesarj1@gmail.com.
} 


\section{INTRODUÇÃO}

Toda interação social, seja de que tipo for, cria no ato mesmo em que se dá uma rede de tensões entre seus participantes, na qual ocorrem conflitos, consensos, disputas, tomadas de posição, negociações mais ou menos bemsucedidas, alianças ou rupturas entre as partes etc. — ou seja, em qualquer interação social se consubstancia o caráter essencialmente político da vida humana, que é inexoravelmente vida social. E se o político caracteriza o humano, a linguagem, atributo exclusivo da espécie, é por conseguinte marcada por esse traço constitutivo da vida em sociedade. A linguagem não "reflete" a sociedade: ela é a própria matéria com que se plasma a existência social, ela cria as interações e é criada nelas e por elas. Falar é fazer, e esse fazer só pode ser político.

Uma noção ingênua e muito difundida é a de que "a língua serve para comunicar", como se a linguagem fosse apenas um meio, um veículo de "transmissão da mensagem" que estabelece um circuito eficiente entre os interlocutores. Mas a língua está muito longe de ser um meio, ela é a própria "mensagem", ela não apenas "diz", ela é "o que se diz". A metáfora do circuito só tem validade se the acrescentarmos a possibilidade, mais do que provável, da ocorrência de curtoscircuitos. Em contraposição àquela concepção ingênua, presente nas teorias linguísticas que se limitam a ver a língua como um "código", Marcuschi (2008, p.64) enfatiza que a língua "é um sistema simbólico geralmente opaco, não-transparente e indeterminado sintática e semanticamente" assim como é "uma atividade social, histórica e cognitiva". A noção de atividade é importante porque descarta a visão da língua como "meio", "instrumento" ou "ferramenta", descarta até mesmo a noção de "usuário" (porque cada falante não apenas "usa" a língua, mas também a constrói, a molda, a transforma, sempre em situações de intercurso verbal) e concebe a linguagem como um fazer. E se tudo o que se faz na vida social é político, o fazer linguagem também é um fazer político.

A prática social da tradução é um palco privilegiado para se observar a ativação desse fazer linguístico-político. O caráter opaco, não-transparente da língua faz da interpretação uma atividade social constante, mesmo nas interações onde se utiliza uma "mesma" língua (as aspas em "mesma" se justificam pela dificuldade de se definir o que seja uma "língua", cf. Bagno, 2011). Se o compartilhamento de uma "mesma" língua não impede (e até favorece) os equívocos e as tensões, as situações que envolvem línguas diferentes deixam ainda mais evidente essa opacidade inerente à linguagem, e mais ainda quando a tradução está implicada em circunstâncias em que a política não é só um "modo de fazer" mas a própria "coisa que se faz". É o caso das 
organizações internacionais, em que a tradução é constitutiva da própria existência dessas entidades.

Aqui se busca estudar a tradução do ponto de vista institucional, abordagem que confere ao ato de traduzir uma "ênfase na produção das traduções (por instituições em condições históricas particulares), em vez da recepção na cultura alvo; prioridade a um foco sociológico na tradução como uma forma única de produção cultural, em vez de um foco psicolinguístico nos processos na mente do tradutor" (MOSSOP, 1988, p.70, grifos do autor).

Para tanto, escolheu-se a União de Nações Sul-Americanas (Unasul) e sua produção documental como objeto de estudo. Este bloco de integração regional da América do Sul é composto pelos doze países do subcontinente (Argentina, Bolívia, Brasil, Chile, Colômbia, Equador, Guiana, Paraguai, Peru, Suriname, Uruguai e Venezuela), ocupa toda sua extensão territorial (com exceção do território pertencente à Guiana Francesa) e engloba uma população estimada em mais de 412 milhões de pessoas, cerca de 65\% dos habitantes da América Latina (NU, 2014, p.8-9).

Devido à quantidade de Estados-membros e sua diversidade linguística, a Unasul adota como idiomas oficiais o português, o inglês, o neerlandês e o castelhano. Essa última língua poderia ser listada como espanhol, mas optou-se por manter a denominação dada pela própria instituição pelo entendimento de que esta foi uma escolha política deliberada por parte dos Estados-membros.

Tendo em vista a configuração plural da Unasul, em termos de idiomas e de países, opta-se por trazer em momentos oportunos da pesquisa, e a título de comparação, a experiência tradutória da União Europeia (UE). Essa instituição também conta com uma multiplicidade de idiomas oficiais (24 no total), representativos de cada país membro, mas apresenta uma estrutura organizacional específica para a produção de traduções que conta com normativas, manuais e tradutores próprios ou contratados externamente, ou seja, a UE desenvolveu estruturas elaboradas para dar a devida atenção à tradução.

No âmbito da Unasul, também seria natural a existência de alguma estrutura institucional que coordenasse o aspecto linguístico da organização, bem como tratasse de como se dá a tradução nesse ambiente, assim como ocorre na UE. A tradução, nesse contexto, parece ser mediadora natural entre línguas diferentes. Pretende-se, assim, estudar o processo de tradução dentro dessa organização sul-americana. Sua importância para os Estudos da Tradução se dá na medida em que avalia a produção tradutória em um contexto institucional onde aquilo que é 
feito produz efeitos nas sociedades dos países envolvidos e, também, efeitos que ultrapassam o âmbito da Unasul.

\section{A UNIÃO DE NAÇÕES SUL-AMERICANAS E SUA PRODUÇÃO DOCUMENTAL}

A concretização da Unasul se deu por meio de seu Tratado Constitutivo, assinado em Brasília em 23 de maio de 2008 - sendo este o discurso comum adotado pelos países membros que define seus objetivos enquanto órgão supranacional, bem como sua própria organização. Ou seja, a partir do momento em que os Estadosmembros ratificam o Tratado, passam a adotar um discurso comum baseado neste documento - as relações de poder, assim como a identidade manifesta da organização, são mediadas por esse discurso que, por sua vez, é proferido por meio de uma linguagem específica, própria de sua natureza de documento jurídico internacional. Destaca-se que "a linguagem é concebida, por um lado, como uma prática social que ao mesmo tempo reflete e delimita os contornos das coletividades humanas e, por outro, como um fenômeno essencialmente variável", e em nível institucional, a linguagem ou o ato de fala "significa, além de usar uma variante frente a outra, privilegiar ou não o uso de uma língua sobre outra em um determinado contexto" (ARNOUX; DEL VALLE, 2010, p.2). É fundamental, pois, compreender de que maneira a linguagem é utilizada em função da identidade da instituição e das relações de poder ali presentes, para encontrar o lugar da tradução neste cenário uma vez que a tradução pode ser vista como ferramenta de propagação do discurso acordado, além de arauto da linguagem adotada.

Nesse sentido, o estudo da tradução nesse contexto deve se preocupar com o fenômeno originário da prática discursiva dentro das organizações internacionais. O produto do discurso - que seriam os documentos da Unasul e possivelmente suas traduções - não pode ser confundido

\footnotetext{
com a operação expressiva pela qual um indivíduo formula uma ideia, um desejo, uma imagem; nem com a atividade racional que pode ser acionada num sistema de inferência; nem com a "competência" de um sujeito falante quando constrói frases gramaticais; é um conjunto de regras anônimas, históricas, sempre determinadas no tempo e no espaço, que definiram, em uma dada época e para uma determinada área social, econômica, geográfica ou lingüística, as condições de exercício da função enunciativa (FOUCAULT, 1987, p.136).
}

Isto é, a tradução, no contexto aqui proposto, precisa ser analisada não pela perspectiva do objeto texto, e suas diversas características particulares quando inserido em ambientes sociais e culturais diferentes, mas por uma visão que a posicione como fruto da prática discursiva acordada pelos Estados-membros da 
Unasul, porque reflete a realidade na qual se evidencia. Na verdade, a tradução seria utilizada com a função de veicular as normativas, acordos e demais documentos, cuja existência

está sempre sujeita ao processo histórico-social. Quando se diz algo em uma época, se diz dentro de um contexto, exterior ao documento, mas constitutivo dele, sobretudo quando se trata de documentos institucionais (...). Além do fato de que o aparecimento de documentos seja um processo controlado daquilo que pode e deve ser dito em determinada época (VIEIRA, 2010, p.46).

Portanto, a produção da tradução na Unasul evidencia-se como algo controlado e feito em determinado contexto com objetivo específico, sua existência é provocada, não é um fato espontaneamente observável. Há, dessa forma, a necessidade de se pensar essa tradução institucional de outra perspectiva, que leve em consideração que a tradução seria fruto de regras que servem, em dado momento, tanto para nortear as relações entre os Estados-membros, quanto, a posteriori, para definir linhas de ação na instituição.

O contexto de produção dessa tradução é essencial para a análise proposta aqui. Organizações internacionais são ambientes ao quais seus Estados-membros cedem parcela de sua soberania e, por consequência, de poder para que sejam legitimados e respaldados os objetivos da organização frente a todos os membros. A perspectiva construtivista das Relações Internacionais representa, nesse momento, uma contribuição privilegiada para uma compreensão elaborada de como as relações de poder influenciam o que se produz em organizações internacionais, na Unasul inclusive, já que esta corrente leva em consideração os já mencionados elementos discursivos e de linguagem como instrumentos de construção política.

Dessa forma, considerando que toda relação política, social e, principalmente, institucional é sustentada por regras que norteiam a ação, a interação e a visão dos agentes com relação àquilo que os cerca, parece natural afirmar que o produto gerado nesses organismos é, também, fruto das regras ali criadas. Na verdade, as regras podem ajudar a entender o comportamento adotado pelos agentes, porque delimitam a capacidade de ação destes. Mas elas só o fazem por terem sido acordadas ou escolhidas, uma vez definidas se configuram como mecanismos sociais: "A escolha das regras, o compromisso com as regras e a desconsideração das regras indicam o tipo de identidade que os agentes sociais estão construindo" (VIEIRA, 2010, p.35).

Aqui entra o entendimento de que a linguagem é uma prática social, uma atividade, conforme definimos acima. É por ela que se torna possível a relação social em si. Como aponta Kowert (1998, p.105), "no nível mais básico, linguagem e 
identidade dependem, assim, uma da outra. A identidade existe por meio da função 'distintiva' da linguagem. Mas a linguagem (...) também depende das identidades de si e do outro".

Ora, se por meio da linguagem, ou do discurso institucional - que, segundo as perspectivas aqui apresentadas, seria ato social e a forma de construção e definição das próprias organizações, bem como de suas vontades acordadas -, são definidas as identidades desses organismos internacionais, seria possível entender a tradução como produto das regras acordadas, e, dessa maneira, produto posterior ao ato de fala: ela é resultado de uma vontade política já legitimada, pois emana das parcelas de poder cedidas pelos Estados-membros à instituição. Nesse caso, a tradução precisaria ser vista como fruto de uma política institucional voltada, especificamente, para questões de línguas. Na verdade,

o processo de tradução em um contexto institucional é uma prática socialmente situada e como tal regida por procedimentos internos. O tipo de instituição também determina quais tipos de discursos e textos são produzidos, e isso também tem implicações para as estratégias de tradução e para a estrutura das traduções produzidas (SCHÄFFNER et al., 2014, p.494).

Retorna-se, assim, ao Tratado Constitutivo que define em seu artigo 23 as quatro línguas oficias da União de Nações Sul-Americanas - português, castelhano, inglês e neerlandês (UNASUL, 2008, p.743). À frente faremos comentários a respeito dessa definição. Neste momento, contudo, vale ressaltar que este documento não estabelece diretrizes para tradução - nem mesmo para produção documental como um todo, este papel é realizado pelo Regimento Geral (RG) da Unasul - mas lança luz sobre o aspecto linguístico e de comunicação da instituição, cujos reflexos na produção documental são evidentes.

Por seu turno, o Regimento Geral, que guia as ações institucionais da organização, instiga um olhar mais atento à produção documental da Unasul, bem como à questão dos idiomas. Diz seu artigo 64: "sem prejuízo ao destacado no Artigo 23 do Tratado Constitutivo, os idiomas de trabalho da Unasul são o castelhano e o inglês" (UNASUR, 2012, p.67). Na verdade, essa escolha de idiomas de trabalho supõe a necessidade de simplificar as rotinas laborais do órgão, que neste mesmo artigo estabelece a utilização apenas dessas línguas:

[as] reuniões dos órgãos e demais instâncias da Unasul serão conduzidas em tais idiomas, com exceção das reuniões do Conselho de Chefes de Estado e de Governo, de Ministras e Ministros de Relações Exteriores e as reuniões ministeriais dos Conselhos da Unasul que contarão com interpretação nos quatro idiomas oficiais da Unasul (UNASUR, 2012, p.67). 
Isto é, na Unasul, apenas os documentos de maior relevância, cuja utilização se dá em/para um nível hierárquico mais alto, são elaborados em todos os idiomas oficiais, enquanto nas rotinas processuais da organização são usados os idiomas de trabalho. Isso também fica claro no artigo 65 do Regimento Geral, no qual se estabelece que a Secretaria Geral da Unasul deve redigir nos idiomas de trabalho os relatórios das reuniões da organização, além de resumos dos temas, listas de participantes, projetos e atos normativos, entre outros documentos.

Outro aspecto a destacar é a página de internet que reúne parte da documentação produzida na Unasul. Só se tem acesso a documentos redigidos em castelhano, apesar da definição dos idiomas de trabalho: o chamado Repositório da Unasul $^{1}$ oferece declarações, resoluções, atas de reuniões, informes, entre outros documentos, todos redigidos nessa língua. Por sua vez, na página de internet principal ${ }^{2}$, que está em castelhano, há possibilidade de acesso a uma página em inglês, porém sem documentos escritos nesta língua, nem mesmo o Tratado Constitutivo ou o Regimento Geral. Alguns exemplos de documentos que deveriam estar disponíveis em todas as línguas, de acordo com o artigo 65 do Regimento Geral da Unasul, são: a Resolução n ${ }^{\circ}$ 2/2014 do Conselho de Ministras e Ministros de Relações Exteriores ${ }^{3}$; e a Declaração de Reunião, dos dias 4 e 5 de dezembro de 2014, do Conselho de Chefes de Estado e de Governo ${ }^{4}$.

$\mathrm{Na}$ verdade, as normativas quanto à redação de documentos na organização sul-americana sugerem um tipo diferenciado de produção documental: os documentos parecem ser redigidos concomitantemente em línguas diferentes, não seriam necessariamente traduzidos, pelo menos não na concepção mais tradicional do que é tradução. Por outro lado, a escolha de duas línguas de trabalho, de acordo com a definição regimental anteriormente explicitada, permite inferir que não há pessoal suficiente para produzir a documentação em todas as línguas e, por conseguinte, também não haveria pessoal para produzir a documentação nas demais línguas quando necessário. De fato, isso se confirma nas palavras de Jorge Yépez, encarregado do Centro de Recursos de Informação da Unasul, que nos explicou em correio eletrônico que a Secretaria Geral da Unasul dispõe de poucos recursos e não conta com tradutores no quadro funcional da instituição: quando são necessários serviços de tradução, contrata-se tradutores na categoria de freelance.

1. Pode ser acessado pelo endereço $<$ http://docs.unasursg.org $>$.

2. Pode ser acessada pelo endereço <http://www.unasursg.org > . Até o dia 15 de dezembro de 2016, esta página estava apenas disponível nos idiomas e particularidades destacados no parágrafo em questão.

3. Disponível em <https://goo.gl/Z6NvXm> . Acessado em 28 de outubro de 2015.

4. Disponível em < https://goo.gl/3LEwux>. Acessado em 28 de outubro de 2015. 
Dessa forma, apesar de as normativas da própria Unasul sugerirem que os conceitos de original e traduzido quando aplicados à rotina da instituição possam ser confundidos, percebe-se não só a possibilidade de emprego da tradução como recurso, mas também a necessidade de seu uso a fim de cumprir o disposto no Regimento Geral e disponibilizar as documentações específicas nos quatro idiomas oficiais.

\section{AS POLÍTICAS LINGUÍSTICAS DA UNASUL PARA TRADUÇÃO}

Neste momento, voltamos à apresentação do panorama das políticas linguísticas para tradução e idiomas na União de Nações Sul-Americanas, por meio de uma descrição da estrutura institucional e normativa voltada para a produção documental e tradutória. Toma-se como fonte inicial dessas informações a documentação já mencionada e uma comunicação inicial por meio de correio eletrônico feita com um dos responsáveis da Unasul pelas produções documentais. A análise se faz inicialmente de modo a identificar uma política linguística da Unasul e, posteriormente, de forma a evidenciar a tradução de fato produzida pela instituição, com base nos preceitos de normas aplicáveis ao caso concreto de tradução institucional.

\subsection{Normativas e regulamentos da Unasul}

A forma como se dá a produção documental da Unasul, e por conseguinte a tradução na instituição, ocorre de acordo com a tipologia documental - adota-se aqui o uso do termo tipologia conforme mencionado por Yépez, responsável pelo Centro de Recursos de Informação da Unasul, que, em correio eletrônico enviado no dia 15 de fevereiro de 2016, utiliza o termo para se referir aos documentos a seguir mencionados. Estabelecem-se dois tipos de documentos distintos, cuja importância determina se são produzidos nas quatro línguas oficiais ou apenas nas duas línguas de trabalho. $\mathrm{O}$ primeiro tipo são as fontes ou instrumentos jurídicos, de acordo com o Artigo 11 do Tratado Constitutivo (UNASUL, 2008, p.739). Encontram-se nesse grupo: o próprio Tratado Constitutivo e seus instrumentos adicionais; os acordos entre os Estados membros celebrados nos moldes do Tratado Constitutivo; as decisões do Conselho de Chefas e Chefes de Estado e de Governo; as resoluções do Conselho de Ministras e Ministros de Relações Exteriores; e as disposições do Conselho de Delegadas e Delegados. Segundo os artigos 64 e 65 
do Regimento Geral da Unasul, estes documentos devem ser elaborados nos quatro idiomas oficiais.

O Regimento Geral vai ainda além da definição dos idiomas. Em seu artigo 70 determina que "os atos normativos que sejam aprovados em qualquer reunião da Unasul deverão ser rubricados pelos representantes dos países nos idiomas em que foram redigidos para sua posterior tradução aos outros idiomas oficiais". Este artigo é, na verdade, o único dispositivo institucional que versa abertamente sobre o uso da tradução na organização. Há, contudo, o que pode ser uma inconsistência terminológica nele: enquanto os artigos mencionados no parágrafo anterior afirmam que as fontes jurídicas devem ser escritas nos quatro idiomas oficiais, este último artigo usa o termo "atos normativos"; de qualquer forma, se também devem ser redigidos em todas as línguas oficias, parece seguro concluir que se trata de documentos de mesma natureza e importância.

Um olhar aprofundado neste artigo 70 do Regimento Geral faz sobressair uma observação importante: os atos normativos (ou fontes jurídicas), além de assinados pelos representantes dos Estados-membros nos idiomas nos quais de fato foram escritos, poderiam ser redigidos em qualquer uma das línguas oficiais, já que seriam posteriormente traduzidos aos demais idiomas. Isso representa um status de igualdade entre os idiomas, de forma que "de um ponto de vista legal e de status, não existem, teoricamente, traduções - apenas versões em línguas diferentes, todas sendo igualmente autênticas" (FISCHER, 2010, p.24). Nesse sentido, a tradução existe, mas, enquanto regida por uma norma institucional, é determinada pelo tipo e extensão de equivalência que a norma lhe permite manifestar (TOURY, 1995, p.60). Ou seja, se a norma institucional define o grau de equivalência das traduções, não importa, do ponto de vista da autoria, qual versão é original ou qual é traduzida, todas têm o caráter de originais.

Por seu turno, o segundo tipo é constituído pelos documentos da rotina administrativa da instituição, sobretudo pelos relatórios de reuniões ordinárias que não envolvem autoridades superiores dos Estados membros. Ainda de acordo com os dois primeiros artigos mencionados acima (64 e 65), estes documentos deverão ser produzidos nas línguas de trabalho (termo utilizado no próprio Regimento), isto é, em castelhano e inglês. É interessante destacar que essa definição de uso dos idiomas oficiais de acordo com o gênero é exposta apenas no Regimento Geral da Unasul. Este documento, na verdade, apesar de aprovado pelo Conselho de Ministras e Ministros de Relações Exteriores (de acordo com o Art. 8, alínea i do Tratado Constitutivo), foi elaborado pela Secretaria Geral, seguindo o disposto no Artigo 10, alínea g, do instrumento jurídico maior do órgão. A utilização de idiomas 
de trabalho pode ser vista, assim, como uma necessidade institucional daqueles que lidam com as rotinas administrativas.

Portanto, se o emprego das línguas oficiais é feito de modo distinto, há de fato uma política linguística institucional para os tipos documentais. A exemplo do que ocorre na União Europeia, onde "os únicos documentos produzidos em todas as 24 línguas oficiais são peças de legislação e documentos políticos de maior importância pública" (EC, 2015, ênfase nossa), na Unasul deveriam ser traduzidos para todos os idiomas oficiais os documentos de maior importância política.

Por outro lado, na União Europeia os demais documentos são traduzidos apenas para as línguas necessárias em cada caso, enquanto que na Unasul são estabelecidos os já mencionados idiomas de trabalho. Ora, deveriam gozar de um mesmo status todos os idiomas oficiais do órgão sul-americano ou talvez ser utilizados de acordo com o caso específico, assim como se dá no caso europeu. De fato, é importante questionar a escolha dos idiomas de trabalho, uma vez que, ao menos em termos de representatividade numérica, territorial e econômica no cenário sul-americano, as línguas com maior destaque deveriam ser o castelhano e o português.

A adoção de idiomas de trabalho ainda poderia, contudo, ser avaliada na perspectiva das normas de Toury. A utilização dos textos em castelhano ou em inglês como idiomas de trabalho, ou ainda como línguas fonte, pode ser entendida como a adoção de uma Norma Preliminar - referente a "fatores que regulam a escolha dos tipos de textos, ou até de textos individuais, a serem importados através da tradução para uma cultura/língua particular em um momento específico no tempo" (TOURY, 1995, p.58) - que faz parte de uma política tradutória, na qual ainda seriam estabelecidas normas operacionais que definiriam as estruturas e características necessárias para que as traduções mantivessem o status de originais.

No entanto, isso também poderia ser explicado, de modo especulativo, por três razões. A primeira porque a Unasul seria, em grande parte, dotada de funcionários cuja língua materna é o castelhano, devido à localização de sua sede (em Quito, no Equador). A segunda porque o inglês é um idioma internacionalmente difundido e, caso necessárias comunicações à comunidade internacional, se daria assim mais acesso àquilo que se faz no bloco. Na verdade, em outros blocos o inglês também ganha destaque, como na União Europeia, onde

ao contrário do Parlamento [Europeu], que por definição é uma instância "aberta", a Comissão [Europeia] é uma instância "fechada" à qual não se tem acesso muito fácil. Ali é onde o trabalho de fato acontece, é onde está o "governo" da Europa. No que tange o uso de línguas, a comissão é bem mais pragmática do que o Parlamento. A escolha linguística se dá por razões de eficiência e não por representatividade. Até os anos 90, o francês tinha uma preponderância 
evidente, mas desde a expansão [da União Europeia] de 1995 e de 2004, o inglês tornou-se a língua dominante. $\mathrm{O}$ inglês é considerado pelos membros da Comissão como uma realidade, como uma espécie de Esperanto da Europa (van SPLUNDER, 2015, p.80, tradução de Julio Cesar Neves Monteiro)

Já a terceira razão seriam, conforme informou Yépez no mencionado correio eletrônico, "limitações de recursos e volume documental, até o momento não se conseguiu traduzir integralmente os documentos jurídicos aos quatro idiomas". Ora, se nem sequer as fontes jurídicas, documentos politicamente mais importantes, puderam ser totalmente traduzidas, o segundo tipo de documentação não teria condições de passar pelo processo de tradução, ficando restrito aos idiomas de trabalho.

A Unasul, conforme exposto no primeiro capítulo, oferece um Repositório dos documentos por ela produzidos. Recorde-se que tais documentos estão disponíveis apenas em castelhano ${ }^{5}$, algo que poderia ter como justificativa os poucos recursos alegados pelo responsável pelo Centro de Recursos de Informação da Unasul. Ele ainda informou que a Secretaria Geral da Unasul contrata intérpretes e tradutores freelance para atender às demandas da instituição. Torna-se mais simples compreender que, embora exista a prerrogativa da igualdade dos idiomas oficiais, sua colocação em prática é de complexa realização e, dessa forma, a adoção de idiomas de trabalho promove-se como opção viável para as comunicações do bloco. Algo semelhante ocorre na União Europeia. De acordo com Fischer (2010, p.24), o princípio de igualdade entre as línguas

não é factível na prática, então na maioria dos casos documentos são rascunhados em uma, duas ou três línguas e depois traduzidos para outras. Como resultado, a desigualdade de fato das línguas oficias da UE faz com que algumas línguas ajam como línguas fonte enquanto outras línguas apenas sirvam como línguas alvo em traduções. Línguas fonte são as geralmente chamadas línguas procedimentais das instituições usadas para comunicações internas.

Portanto, se numa organização internacional com uma elaborada estrutura institucional voltada para a tradução, como a União Europeia, há complicações para traduzir para todos os seus idiomas oficiais a documentação por ela produzida, compreende-se o motivo da ausência, à primeira vista, de versões em outras línguas de fontes jurídicas da Unasul. Para compreender melhor a situação, fomos buscar junto à própria instituição mais informações a respeito de suas normativas voltadas para línguas e para a tradução de seus documentos.

5. De acordo com as consultas realizadas durante o desenvolvimento da pesquisa até a data da última consulta (15 de dezembro de 2016), de fato, foram encontrados apenas documentos em castelhano no Repositório da Unasul. 


\subsection{Visita à Unasul e dados levantados ${ }^{6}$}

Para a aferição das informações necessárias à pesquisa, elaborou-se um roteiro para realização de entrevista com representantes da União de Nações SulAmericanas. O roteiro foi redigido de modo a esclarecer, durante a entrevista, as normativas mencionadas acima e levantar outras normativas que porventura existam e não sejam de conhecimento público, identificar suas aplicabilidades na prática, descrever o procedimento de produção dos documentos do órgão e verificar o panorama da produção de traduções na instituição, além de compreender a relação da tradução e dessas normativas nas rotinas da instituição.

As visitas à sede da União de Nações Sul-Americanas, localizada na cidade de Quito, capital do Equador, ocorreram nos dias 12 e 14 de setembro de 2016. Participaram da entrevista dois representantes da Unasul: Jorge Yépez, encarregado do Centro de Recursos de Informação Eduardo Galeano e do Arquivo da Unasul; e Erubys Chirinos, Chefe do Centro de Comunicação e Informação (CCI) da Unasul, encarregada de escolher a documentação a ser traduzida e de realizar seus trâmites burocráticos.

O primeiro aspecto esclarecido refere-se à definição de castelhano e inglês como línguas de trabalho. No momento da elaboração do Regimento, os delegados dos Estados-membros teriam decido pelo castelhano dada a localização da sede da Unasul e do número de países membros do órgão com este idioma oficial, e pelo inglês por ser uma escolha prática, visando dar à comunidade internacional facilidade ao acesso à Unasul e ao trabalho que desenvolve. Não haveria, segundo os representantes da Unasul, nenhuma motivação ideológica ou política.

O segundo ponto tratado na entrevista diz respeito ao processo de produção dos documentos da instituição. Chirinos foi categórica ao afirmar que a documentação é elaborada, em geral, em castelhano e depois traduzida aos demais idiomas oficiais, no caso de documentos originários de reuniões de Chefes de Estado ou Chanceleres, ou para o inglês nos demais casos. Afirmou ainda que, em caso de uma proposta brasileira, por exemplo, é realizada sua tradução aos demais idiomas, enquanto que Guiana e Suriname teriam preferência por utilizar o inglês para suas comunicações.

Na sequência da entrevista, buscamos averiguar o panorama dos documentos de fato traduzidos, tanto os tipos (instrumentos jurídicos e demais documentos)

6. Maiores detalhes a respeito da visita à Unasul, do roteiro da entrevista, assim como sua descrição completa, e do dados podem ser verificados na dissertação de Mestrado que originou o artigo, de autoria de Guilherme Queiroz. Disponível em < http://repositorio.unb.br/handle/10482/23516>. 
quanto a quantidade de documentos. A deficiência orçamentária foi reiterada pelos representantes da Unasul, que reconheceram haver muitos documentos ainda não traduzidos: estão em fase de tradução de toda documentação dos últimos três anos que, por força regimental, deve ser traduzida aos quatro idiomas oficiais.

Tivemos acesso a alguma documentação que já estava traduzida: recebemos versões de quatro documentos de uma Reunião de Chanceleres (uma minuta de Declaração sobre as ilhas Malvinas; a Declaração de Reunião Ordinária; uma Declaração Especial; e a Ata de Transferência da Presidência Pro Tempore) em castelhano e em inglês.

Outra questão tratada na entrevista foi a contratação de tradutores. Até aquele momento, a Unasul ainda contava com o serviço de tradutores freelance. Por outro lado, fomos informados de que fora aprovada uma reestruturação no quadro da Secretaria Geral e que em breve seriam contratados um tradutor chefe e dois tradutores para o quadro funcional da Unasul.

Com relação às interpretações no âmbito da Unasul, é importante destacar dois pontos que surgiram durante a entrevista. $O$ primeiro refere-se à contratação de intérpretes para realização de videoconferências: a interpretação é utilizada nas ocasiões em que participam Guiana e Suriname. Segundo Chirinos, "no resto dos casos, se não participam esses dois países, não é necessário contratar intérpretes, porque a maioria fala espanhol". O segundo ponto que merece destaque aqui é essa opção do Suriname de preferir utilizar a documentação em inglês. Conforme averiguado, os representantes desse país não costumam usar o neerlandês, preferindo pronunciar-se frente a um documento enviado pela Presidência Pro Tempore em inglês.

Finalmente, no último tópico da entrevista, buscamos averiguar a existência de normativas institucionais, além das regimentais, voltadas para a produção documental e de traduções. Os representantes da Unasul apontaram, então, que está em curso uma reestruturação administrativa da Secretaria Geral que permitirá a cada setor regulamentar seus próprios procedimentos, apesar de já existirem rascunhos de regulamentos e manuais de uso já escritos, inclusive um para tradução, que esperam aprovação.

\section{ANÁLISE}

A partir das determinações regimentais da Unasul e do conteúdo da entrevista, propõe-se na sequência a análise de quatro aspectos principais, e de algumas de suas particularidades: a escolha de dois idiomas de trabalho, em detrimento dos demais 
idiomas oficiais; a produção das traduções com base na relação entre status dos idiomas e corpus documental para cada idioma; o processo de realização da tradução, o manual, ainda indisponível para consulta, e a contratação de tradutores.

\subsection{Dos idiomas de trabalho}

A definição dos idiomas de trabalho constitui uma política linguística e tradutória na Unasul. A escolha do castelhano como idioma de trabalho é coerente com a localização geográfica da sede da instituição. Outro critério para essa escolha poderia ser a representatividade desta língua para parcela da população e quantidade de nações que compõem o bloco - dos doze países membros, apenas três não têm essa língua como idioma oficial.

Também em termos de representatividade referente à população, o português seria outra escolha lógica como idioma de trabalho para a Unasul. Afinal, a América do Sul tem mais de 412 milhões de habitantes, dos quais mais de 200 milhões são brasileiros ${ }^{7}$. Isto é, os falantes de português representam quase metade da população do bloco, o que poderia ser visto como motivo suficiente para a escolha deste idioma como língua de trabalho. Além disso, a representatividade econômica do Brasil para o funcionamento da Unasul também poderia ser determinante para uma maior importância do idioma oficial do país no âmbito do órgão. Para o exercício de 2016, o Brasil contribuiria com quase $40 \%$ do orçamento da Unasul, repassando um montante superior a US\$ 4,2 milhões, o segundo país com maior contribuição nesse orçamento seria a Argentina, com repasse de quase US\$ 1,8 milhão (UNASUR, 2015, p.3).

Por seu turno, a determinação do segundo idioma de trabalho da Unasul parece ter sido pautada pelo panorama de globalização no qual se insere a instituição, recordando o que disse o Sr. Pedro Sassone a respeito de se propiciar à comunidade internacional o acesso ao órgão, ou seja, facilitar a comunicação da Unasul com o resto do mundo. De fato, o inglês é o idioma dominante em nível internacional, sua difusão é inegável e a língua está presente em diversos contextos distintos. Dentro da própria Unasul, a adoção do inglês como idioma de trabalho favorece não apenas à Guiana (cujo idioma oficial é o inglês), mas também o Suriname que, conforme exposto na entrevista, utiliza esta língua para suas manifestações no bloco em vez do neerlandês.

7. Informação disponível em <http://www.ibge.gov.br/apps/populacao/projecao/> . Acesso em 20 de dezembro de 2016. 
Não obstante, chama a atenção o fato de uma instituição que afirma em seu próprio Tratado Constitutivo ter como objetivo "eliminar a desigualdade socioeconômica (...) e reduzir as assimetrias no marco do fortalecimento da soberania e independência dos Estados" (UNASUL, 2008, p.732), mas que adota como idioma de trabalho uma língua que é instrumento de avanços imperialistas de países como o Reino Unido, no século XIX e início do século XX, e os Estados Unidos, depois da Segunda Guerra Mundial. Países cujas imposições neoliberais marcaram fortes crises econômicas nos países latino-americanos. Ora, de um ponto de vista político e econômico periférico e apesar de ser o inglês idioma oficial da Guiana, dá-se maior importância ao que é externo à organização em detrimento do que ali é natural ${ }^{8}$.

Nesse sentido, não se pode desvincular essa análise de um aspecto ideológico que lhe é inerente. A partir do momento em que se opta pelo inglês como idioma de trabalho no Regimento Geral, seu uso é legitimado e a discussão sobre esse uso deixa de ser realizada de modo que os países passam a não questionar a norma. Retomo a fala de Chirinos na entrevista sobre a utilização de interpretação em videoconferências na Unasul: quando Guiana e Suriname não participam, não se contrata intérpretes para a videoconferência "porque a maioria fala espanhol". Desta afirmativa, pode-se inferir três possibilidades: 1) o Brasil não participa das videoconferências da Unasul (não sendo necessária a interpretação para o português) ${ }_{2} 2$ ) o Brasil não exige a interpretação, assim como os demais países não exigem um intérprete para o português; ou, ainda, 3) o Brasil opta por comunicar-se em castelhano.

A primeira inferência supõe uma falta de interesse em participar das atividades da Unasul por parte do Brasil, ideia que não condiz com a contribuição financeira do país à instituição. Na realidade, o projeto de integração regional sulamericana pôde-se desenvolver ao ponto de criação da própria Unasul graças às ações brasileiras de inserção regional que encontraram respaldo e reciprocidade nos projetos de política externa dos demais países-membros. Logo, essa possibilidade só faria sentido se se tratasse de um tema que não interessa ao Brasil. Por sua vez, a segunda inferência pressupõe a ideia errônea de que castelhano e português, por serem línguas próximas, seriam mutuamente inteligíveis para seus falantes.

8. Vale ressaltar que o uso do termo natural faz referência superficial aos idiomas falados oficialmente na América do Sul (português, neerlandês e castelhano). Evita-se entrar na discussão a respeito dos idiomas indígenas, que de fato são naturais deste continente e que têm status de idioma oficial em nível nacional para alguns países, assim como alguns idiomas que, ainda que não oficiais, os superam em número de falantes (como o sranan, língua crioula do Suriname, ou o creolese, idioma crioulo da Guiana), para não haver fuga ao tema principal do trabalho. 
Essa possibilidade contradiz o princípio geral da comunicação em organismos internacionais, o suposto entendimento entre os países-membros por meio de uma comunicação eficaz baseada na tradução - e, especificamente no caso da Unasul, o próprio destaque regimental para a necessidade de versões de certos documentos em todos os idiomas oficiais. Por fim, a terceira hipótese sugere que todos os representantes brasileiros junto à Unasul têm proficiência linguística em castelhano, sendo capazes de desenvolver seus trabalhos nesse idioma sem necessidade de qualquer tipo de tradução - o que não se pode afirmar com segurança dada a alta rotatividade do pessoal diplomático, o que faz com que, em algum momento, algum representante brasileiro na Unasul não seja inteiramente capacitado para se comunicar apenas em castelhano.

A despeito dessas possibilidades, o fato é que há um atrito por parte de alguns países com relação ao uso do português e o que isso representa para eles em nível regional. No âmbito do Mercosul, por exemplo, legitimou-se a promoção de seus dois idiomas oficiais, o português e o castelhano' ${ }^{9}$, de uma forma conceitualmente simples por meio do estímulo do ensino desses idiomas como línguas estrangeiras. Segundo Diniz (2016, p.101), os países lançam mão de políticas linguísticas exteriores para a promoção de seus idiomas nesse tipo de situação e, no caso do Brasil, essas políticas são vistas "como parte de um movimento neocolonizador e neoimperialista brasileiro". O pesquisador aponta ainda que esse discurso é encontrado inclusive em matérias jornalísticas veiculadas no Paraguai e no Peru, cuja retórica destaca o avanço e crescimento econômico brasileiro, mostrando o país como inclinado em ações de natureza imperialista em nível regional.

Este exemplo demonstra que, se num bloco menor que a Unasul, a promoção do português é dificultada, num contexto mais amplo não seria mais simples. Por outro lado, em termos imperialistas, o castelhano teve uma difusão mundo afora tão imperialista quanto o português. Na realidade, o contexto latino-americano "não faz mais que reproduzir uma assimetria linguística própria das grandes potências imperiais que repartiriam entre si os territórios do Novo Mundo: Espanha e Portugal" (LINK, 2016, p.190).

Nesse sentido, a adoção de posturas contrárias à adoção de português ou castelhano na América do Sul não contribui para o desenvolvimento dos processos de integração regional, mas reforça assimetrias herdadas do passado colonial e periférico dos países que compõem a Unasul, algo que contradiz os próprios objetivos da instituição. Há de se ressaltar que, antes da própria criação do órgão,

9. Cabe destacar que o guarani também se tornou idioma oficial do Mercosul, ainda que permaneçam como idiomas de trabalho o português e o castelhano. 
realizou-se em Brasília, em novembro de 2007, o Seminário Brasil-Argentina sobre Ensino e Certificação do Português e do Espanhol como segundas línguas, que discutiu ações para difusão do bilinguismo desses idiomas no Mercosul e na América do Sul (ARNOUX; NOTHSTEIN, 2014, p.14). Reconhece-se, assim, que o protagonismo do português e do castelhano no continente.

Além disso, nas esferas acadêmicas de estudo da difusão dos idiomas entre os países da região, parece haver consenso quanto à ideia de que a difusão dessas línguas de modo igualitário é importante. De acordo com Arnoux (2008, p.14),

tanto se nos atentarmos à dimensão cultural quanto à cívica da integração sul-americana, o conhecimento das línguas da região torna-se fundamental: por um lado, é um dos modos de alcançar a compreensão dos povos que a compõem e de se vincular com eles e, por outro lado, abre a possibilidade de que os cidadãos participem plenamente em distintas instâncias políticas regionais.

Dessa forma, apesar dos dispositivos regimentais da Unasul legitimarem a definição dos idiomas de trabalho, e ainda que sejam consideradas as justificativas apresentadas por seus representantes de restrições orçamentárias e da tentativa de facilitar o acesso internacional à Unasul, a escolha do inglês como idioma de trabalho traz indícios de que questões ideológicas podem estar na origem dos empecilhos à escolha do português como idioma de trabalho, contradizendo a trajetória e o discurso integracionista da instituição. Não se pode negar a necessidade do inglês como idioma oficial da instituição, principalmente por ser idioma oficial de um dos países membros. No entanto, é notória a importância do português na América do Sul. De fato, "para nós, hoje seria praticamente impossível sustentar uma comunidade imaginada que excluísse o Brasil (sua economia, sua cultura, sua literatura)" (LINK, 2016, p.190). Mais ainda, ao observar que os idiomas de trabalho são usados na redação de documentos de menor importância hierárquica ou de menor impacto político na instituição, não faria sentido desejar que esses documentos fossem difundidos internacionalmente. Afinal, não há tanta relevância internacional numa lista de participantes de uma reunião de delegados quanto numa resolução de uma reunião de chanceleres. Consideramos, assim, que - sendo estritamente necessário escolher dois idiomas em detrimento dos demais - teria sido mais acertada a definição de castelhano e português como idiomas de trabalho, de modo que a tradução seria utilizada para auxiliar no andamento dos trabalhos da instituição, quando as comunicações nesses idiomas não fossem suficientes - algo que já ocorre. 


\subsection{Relação status-corpus nas produções da Unasul}

Qual seria a relação entre o status dos idiomas e o corpus para cada idioma oficial - gerada pela definição dos idiomas oficiais e de trabalho - em determinadas produções documentais na instituição? Para responder, utilizamos o modelo de análise de Calvet (2007, p.49-57), segundo a proposta de Chaudenson de análise da relação das funções de uma língua em determinados países (o status da língua) e do material produzido nela (o corpus da língua). Este instrumento busca visualizar a situação linguística de um país com vistas a elaborar diagnósticos do uso das línguas e propor ações que porventura sejam necessárias de acordo com os objetivos dos tomadores de decisão. Embora Chaudenson trabalhe essa proposta em $1990^{10}$ para analisar, com a utilização de gráficos, a relação entre status e corpus da língua francesa em meio a outras línguas faladas em países francófonos, Calvet demonstra que é possível utilizar as informações geradas tanto para aferição sobre o real uso das línguas quanto para decidir sobre a necessidade de intervenções. Aqui, este modelo será referência para reproduzir graficamente a funcionalidade dos idiomas na Unasul e seu uso na produção de documentos.

Antes de apresentar o gráfico gerado a partir das informações constatadas na pesquisa, é importante esclarecer a escolha do material que compõe o corpus em questão. De modo geral, o corpus deveria ser constituído por todo documento e produção textual da instituição. No entanto, além dos documentos cujo acesso é público e disponível no Repositório da Unasul - todos em castelhano como informado anteriormente -, foram encontradas apenas as versões do Tratado Constitutivo (TC) em todos os idiomas oficiais e foram disponibilizados, apenas nos idiomas de trabalho, quatro documentos de uma reunião de chanceleres. Assim, em termos quantitativos, há poucos documentos disponíveis - o que inviabiliza inclusive uma análise das traduções em si, de forma que foi necessário delimitar o corpus não pela quantidade de documentos, mas por grupos de documentos.

Nesse sentido, o gráfico a seguir exibe a relação entre o status dos quatro idiomas oficias da Unasul e o corpus produzido nessas línguas, cuja caracterização é dada conforme os seguintes grupos de documentos: 1) Tratado Constitutivo, posto em separado por se tratar do principal instrumento jurídico e ser o único documento encontrado em todos os idiomas oficiais; 2) Regimento Geral, também em separado por ser o documento que rege as ações institucionais da Unasul, mas encontrado

10. A proposta de Chaudenson refere-se à elaboração de gráficos para estabelecer a relação statuscorpus em casos determinados de análise. No entanto, a delimitação de planejamento de status e planejamento de corpus como modalidades de planejamento linguístico foram propostas por Kloss em 1969. 
apenas em castelhano; 3) instrumentos jurídicos, em tese disponíveis nos quatro idiomas, mas de fato observados apenas nos de trabalho; 4) documentos rotineiros e aqueles que não estejam relacionados no Artigo 11 do TC, apenas redigidos nos idiomas de trabalho; e 5) página de internet da Unasul, por se tratar do principal instrumento comunicativo da instituição com o público e com a comunidade internacional, publicada apenas nos idiomas de trabalho.

Gráfico 1. Relação status-corpus da Unasul

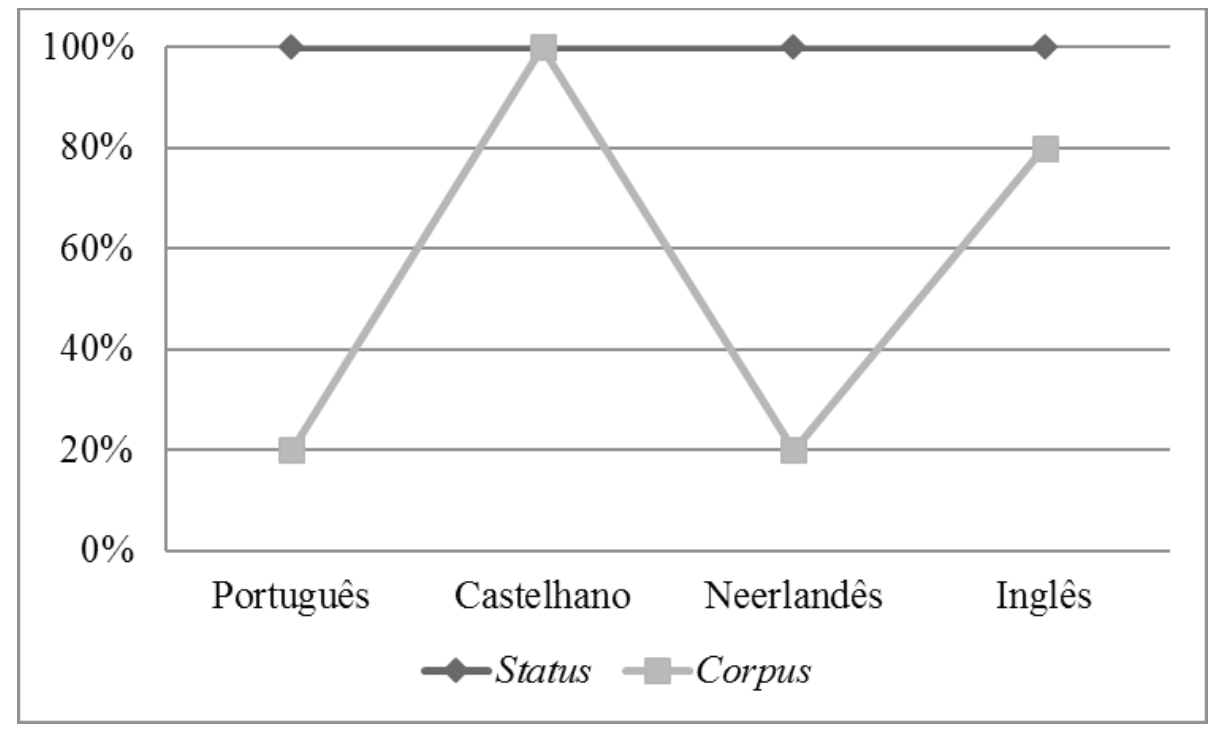

A representação do status dos idiomas é $100 \%$ em todos os casos devido à oficialidade de cada uma dessas línguas: todas são igualmente oficiais de acordo com o TC. Por sua vez, o corpus é contabilizado em função de ter sido encontrado pelo menos um documento de cada um dos grupos acima informados. Logo, o castelhano configura corpus de $100 \%$ por apresentar ocorrências de documentos nos cinco grupos anteriormente mencionados. Já para o inglês a porcentagem cai para $80 \%$ porque não se encontrou nessa língua, em meios eletrônicos ou físicos, o Regimento Geral. Quanto ao português e ao neerlandês, a porcentagem de 20\% de corpus é a mesma, uma vez que apenas foi evidenciada uma versão do Tratado Constitutivo para cada um destes idiomas, isto é, não foi encontrada nenhuma versão nesses idiomas de documentos dos quatro grupos restantes.

Dessa forma, o Gráfico 1 ilustra a disparidade de tratamento das línguas na Unasul. Apesar de serem todos oficiais, verificou-se que não há produção de documentos equivalentes em todas as línguas. Obviamente, o artigo 65 limita 
parte da produção de documentos a castelhano e inglês, não está prevista a versão daqueles documentos de natureza rotineira e de menor importância hierárquica em português e em neerlandês. Contudo, até mesmo em inglês, que é um dos idiomas de trabalho, não se verifica uma versão do RG. Também cabe observar que as versões em inglês dos documentos do quarto grupo não estão disponíveis no Repositório, apenas tive acesso a algumas delas porque Yépez as enviou.

Tendo em vista este panorama, cabem algumas observações. A presença de corpus nos cinco grupos propostos para o castelhano condiz com a legitimidade do idioma enquanto oficial e de trabalho e demonstra que a instituição segue suas disposições constituintes e regimentais com relação à documentação produzida nessa língua. Chama a atenção, porém, o fato de não haver versão em inglês do Regimento Geral, sendo que esta língua se assemelha ao castelhano em termos regimentais e que em todos os outros grupos foi possível verificar seu uso. Por seu turno, português e neerlandês parecem não dispor do mesmo prestígio dos demais idiomas possivelmente por não serem também idiomas de trabalho. Mas a não existência de uma versão da página de internet da Unasul nesses idiomas sugere uma negligência para com essas línguas - a página configura-se como meio inicial de contato e acesso à instituição, a falta de versões em português e em neerlandês dificulta que o público brasileiro e o surinamês possam compreender a importância da instituição, bem como inviabiliza sua atuação em âmbito regional. A título de comparação, a União Europeia disponibiliza sua página de internet principal em 24 idiomas diferentes ${ }^{11}$, demonstrando que, apesar de não ser possível elaborar versões dos documentos dessa instituição em todos os idiomas oficiais, se deve dar a devida atenção a todas as línguas para respeitar seu status igualitário.

Não obstante, há a possibilidade de essa negligência por parte da Unasul não ser proposital, mas sim um reflexo da contingência orçamentária da instituição da qual falaram Chirinos e Yépez. Isso explicaria - apesar de indícios de uma postura ideológica da instituição com relação à escolha dos idiomas de trabalho e ao uso dos demais idiomas -, além da falta de versões de documentos desses grupos em português e neerlandês, também a não existência de versão em inglês do RG.

Um último aspecto referente ao corpus merece destaque. Na entrevista, os representantes da Unasul afirmaram que são feitas traduções dos documentos da instituição, ainda que sua maioria não seja traduzida, e que eles nos enviariam as versões de alguns documentos de uma reunião de chanceleres. Recebemos versões apenas em castelhano e inglês - são justamente esses documentos que

11.Página principal da União Europeia. Disponível em $<$ https://europa.eu/ $>$. Acesso em 7 de janeiro de 2017. 
contabilizamos como instrumentos jurídicos e documentos rotineiros para inglês no gráfico acima. Na verdade, segundo o artigo 65 do RG, dos quatro documentos dois teriam que ser traduzidos para os quatro idiomas (por serem declarações de reunião de chanceleres) e os outros dois teriam versões apenas nos idiomas de trabalho (por um ser um projeto de declaração e o outro ser uma ata). Isto é, não estavam disponíveis as versões nos outros dois idiomas ou ainda não estavam traduzidas. $\mathrm{O}$ que pode ser deduzido disso é que se produz tradução na Unasul, mas essa produção está ainda incipiente. Não é possível afirmar realmente se existem versões, pelo menos dos instrumentos jurídicos mais importantes, para português e neerlandês, uma vez que não nos permitiram visitar o arquivo da instituição, não nos enviaram nenhum documento nesses idiomas e não há no Repositório versões de documentos a não ser em castelhano. Isso é algo que deve mudar eventualmente, considerando a informação dada na entrevista de que o Repositório teria sido programado para receber as versões em língua inglesa dos documentos.

\subsection{Processo tradutório, manual e contratação de tradutores}

A entrevista com Chirinos e Yépez pôde esclarecer o procedimento seguido pela Unasul para produção de seus documentos nos idiomas oficiais. Segundo averiguado, a tradução é utilizada quando se faz alguma proposta a partir de idiomas diversos do castelhano, mas uma vez iniciado o trâmite da documentação na Unasul, o texto é redigido em castelhano e em inglês em algumas situações. Segundo os entrevistados, a tradução para as demais línguas oficiais é feita nas situações em que os documentos produzidos tiverem saído de reuniões de chefes de Estado ou chanceleres. Aqui já se verifica uma inconsistência com os ditames regimentais, na medida em que, por força do Artigo 65 do RG, também documentos das reuniões de nível ministerial dos Conselhos da Unasul deveriam ser traduzidos para todas as línguas.

De certo modo, reduzir o escopo de incidência da tradução - deixando de traduzir os instrumentos jurídicos de nível ministerial, por exemplo - seria uma forma de mitigar as já mencionadas limitações financeiras. Contudo, uma ação não deliberada nesse sentido resultaria no desrespeito ao consenso manifesto no RG, reflexo do próprio acordo maior que é o TC. Ao passo que qualquer mudança nos trâmites internos da Unasul precisaria ser discutida entre os Estados-membros, ainda que visando a redução das atividades tradutórias para adequá-las ao orçamento disponível.

Na realidade, a Secretaria Geral tem que trabalhar seguindo as diretrizes estabelecidas e com o dinheiro disponível. Os representantes da Unasul com quem 
conversamos demonstraram o tempo todo que os funcionários do órgão buscam se adequar a essas normas e cumprir com suas obrigações, mantendo, assim, a Unasul funcionando. Foi possível perceber que a instituição tem uma estrutura muito grande e atribuições de mesmo vulto. Os funcionários não são suficientes para desempenhar todas as funções que a SG demanda e, provavelmente, o orçamento é sim limitante - faz sentido, então, que a tradução seja colocada em segundo plano nas prioridades da instituição, apesar de ser uma atividade mandatória: até o momento da visita, não havia sequer um tradutor no quadro de funcionários da Unasul.

Outro aspecto que cria obstáculos nesse panorama é a relação entre a Secretaria Geral e as autoridades políticas. A SG tem pouca autonomia decisória e suas ações se restringem àquelas possibilitadas pelas contribuições da Presidência Pro Tempore - ocupada a cada ano por um país diferente. Conforme expôs Chirinos, a SG não tem como controlar a documentação produzida no órgão, ou sequer proceder à sua tradução, se a Presidência Pro Tempore não envia essa documentação. Ora, se as autoridades máximas da Unasul não colaboram com a própria instituição, não há como esperar que seu funcionamento seja condizente com sua proposta normativa.

Por outro lado, esse cenário tem sofrido mudanças que visam melhorias nas atividades da SG. No orçamento da Unasul para o ano de 2016, já estavam previstos recursos para a contratação de dois tradutores e de um tradutor chefe para o Centro de Comunicação e Informação, órgão chefiado por Chirinos. De fato, no mês seguinte à visita, foi publicado edital ${ }^{12}$ para realização de concurso de contratação de alguns funcionários para a Unasul, entre eles os cargos destacados do orçamento. Publicado em 17 de outubro de 2016, o edital anunciou salários de US $\$ 2.327,00$ para cada tradutor e de US $\$ 4.072,00$ para o tradutor chefe, montantes maiores até que o previsto inicialmente no orçamento de US\$2.000,00 e US\$ 3.000,00 respectivamente.

A contratação de tradutores para compor o quadro funcional da Unasul constitui um fator fundamental para suas atividades tradutórias. Ainda que a instituição dispusesse de algum recurso financeiro para contratar serviços freelance de tradução e ainda que estes tradutores fossem qualificados para o serviço, é improvável que houvesse uma consistência terminológica, de registro ou de estrutura no material traduzido por eles - na entrevista ficou claro que não havia trabalho de

12. Convocatória pública para apresentar interesse para cargos locais na Secretaria Geral da Unasul. As inscrições tiveram início em 17/10/2016 e findaram em 28/10/2016, com resultado previsto para 18/11/16. Disponível em: <http://www.unasursg.org/sites/default/files/CONVOCATORIA\%20 OCTUBRE\%2017\%202016.pdf>. Acesso em 20 de outubro de 2016. 
revisão até então, confiava-se no trabalho destes tradutores por sua experiência e pelos serviços anteriormente prestados. Não buscamos questionar a qualidade dos serviços prestados pelos freelance, mas estes tradutores costumam realizar traduções de diversas naturezas e, eventualmente, de forma concomitante. Além disso, em uma organização internacional, a consistência das versões em línguas distintas dos documentos é importante para manter um entendimento homogêneo por parte dos Estados-membros.

Aqui, torna-se relevante destacar o procedimento de seleção previsto no edital, bem como os requisitos buscados nesses profissionais. Inicialmente, se realizaria uma análise de antecedentes dos candidatos, que busca averiguar requisitos básicos como nacionalidade (devem ser naturais de algum Estadomembro), formação acadêmica relevante para o cargo, entre outros, e requisitos específicos do cargo. Para o cargo de tradutor-chefe, estão previstos sete grupos de requisitos que envolvem as seguintes características: experiência de oito anos como tradutor; formação acadêmica em línguas, tradução e afins; manejo de ferramentas de edição de texto; conhecimentos sobre técnicas de tradução e redação; habilidades específicas sobre leitura, organização e comunicação interpessoal; proficiência em idioma diferente da língua materna comprovada por certificado de instituição reconhecida, sendo pelo menos um idioma de trabalho e outros dois ou mais dos idiomas oficiais; e idade superior a 25 anos. Para o cargo de tradutor, estão mantidos os mesmos sete grupos de requisitos com apenas duas diferenças: experiência de cinco anos como tradutor e saber manejar fontes de informação.

Em um segundo momento dessa seleção, seria realizada uma entrevista apenas com os candidatos aprovados na fase de antecedentes. Mas não foram publicados detalhes a respeito da entrevista e de como ela seria feita. Ainda que esses critérios possam ser discutidos em termos de sua eficácia ou objetividade na contratação de profissionais melhor qualificados, percebe-se uma tentativa de selecionar profissionais com competências necessárias para lidar com a tradução da Unasul.

Dessa forma, a contratação de tradutores efetivos na Unasul demonstra o compromisso da instituição com seus próprios marcos regimentais e estabelece uma preocupação definitiva com tradução em nível institucional - estes tradutores, inclusive o chefe, terão a incumbência de pôr em curso uma estrutura de tradução institucional ainda incipiente, com todas as particularidades de um ambiente multilíngue. Obviamente, três pessoas não são suficientes para conseguir produzir versões em até mais três idiomas de diversos documentos já existentes e que ainda virão a existir. Este é um processo que, além de demandar tempo, exige o 
conhecimento de múltiplas línguas, o que poucos têm. Em termos ideais, a Unasul deveria ter contratado pelo menos mais dois tradutores, para contar com um tradutor para cada idioma.

Por outro lado, instituições que já contam com um corpo de tradutores próprio ainda utilizam serviços freelance em casos específicos - algo que ocorre na União Europeia. Ali, além de se contratar tradutores dessas duas naturezas, há a disposição de estrutura física para o trabalho dos tradutores, existem publicações ${ }^{13}$ sobre a atividade tradutória europeia e se elaborou, no caso do Departamento de Língua Portuguesa da Comissão Europeia, um Guia do Tradutor ${ }^{14}$ composto por informações a respeito dos tipos de documentos da UE, instruções sobre estrutura dos textos e disposição gráfica destes, entre outras informações pertinentes para o tradutor.

Tendo em vista o exemplo da UE, a Unasul mostra-se em um patamar promissor. Embora conte com um número de idiomas oficiais consideravelmente menor que a UE, a Unasul tem buscado se estruturar para o desempenho da atividade tradutória - como visto na entrevista, já se elaborou um manual para tradução, mas sua aprovação pelas autoridades sul-americanas continua pendente. Ou seja, outra vez há necessidade de uma atuação mais assertiva dos representantes dos países na rotina regional. Assim, verifica-se que a Unasul tem potencial para melhorias no desenvolvimento da tradução institucional. Concretizada a contratação dos tradutores, haverá pessoal na instituição cujo objetivo é trabalhar a tradução, fazer uso do manual a ser aprovado e possibilitar, futuramente, uma análise da tradução institucional na Unasul mais aprofundada, voltada também para questões textuais, terminológicas ou também profissionais.

\section{CONSIDERAÇÕES FINAIS}

A pesquisa aqui descrita foi desenvolvida com o intuito de descrever os procedimentos relativos à tradução em nível institucional, na perspectiva da política linguística aplicada aos Estudos da Tradução. A União de Nações Sul-Americanas mostrou-se um objeto de análise pertinente por proporcionar um ambiente com multiplicidade de idiomas oficiais, fato que sugeria, inicialmente, a necessidade de uso da tradução para desempenho das atividades da organização. Verificou-se que

13. Publicações da União Europeia sobre tradução. Disponível em <http://cdt.europa.eu/PT/ documentation/Pages/Publications.aspx > . Acessado em 07 de janeiro de 2017.

14. Disponível em < https://infoeuropa.eurocid.pt/files/database/000067001-000068000/000067299. pdf $>$. Acessado em 23 de junho de 2015. 
a tradução não só é ferramenta de manifestação do consenso entre os Estadosmembros da Unasul, mas também pode ser vista como fruto do próprio acordo entre esses países. Optou-se, assim, por analisar a tradução na qualidade de produto de uma política institucional e não como o produto texto em si.

A visita à sede da Unasul foi essencial para esclarecimento de aspectos presentes no Tratado Constitutivo e no Regimento Geral referentes aos idiomas da instituição e à tradução em si, além de ter possibilitado uma melhor compreensão do funcionamento dessa organização e de seus processos tradutórios. Foi possível observar que a Unasul conta com a estrutura física necessária para a realização de seus propósitos políticos e administrativos, mas tem um considerável déficit de funcionários - até então não havia um único tradutor do quadro funcional. Apesar disso, é válido destacar o trabalho realizado pelos funcionários que estão lá. Embora haja limitações orçamentárias, a Secretaria Geral do órgão, com o auxílio desses trabalhadores, tem desempenhado seu papel e tem conseguido produzir algumas traduções com a contratação de profissionais na qualidade de freelance.

Pode-se concluir desse cenário que, além de maior dotação financeira, a instituição necessita um maior engajamento de suas autoridades políticas nas atividades ali realizadas. Por outro lado, essa pouca atuação dos representantes das nações junto à Unasul pode ser reflexo de mudanças nas políticas externas desses países. A Unasul foi criada num contexto em que os principais países da região tinham governos que se qualificavam como progressistas e interessados numa integração maior com vistas, entre outras coisas, a resistir ao avanço do neoliberalismo avassalador que domina o panorama mundial neste início de século. Em anos recentes, porém, a desestabilização ou desmantelamento sistemático desses governos (como o caso do golpe parlamentar que destitui, em 2012, o presidente paraguaio Fernando Lugo, roteiro repetido no Brasil em 2016, com a deposição da presidenta brasileira Dilma Rousseff, a crise econômica na Venezuela etc.), estimulada quando não patentemente financiada pelos interesses do grande capital internacional, sobretudo estadunidense, decerto tem contribuído para a falta de engajamento dos Estados-membros na ampliação do escopo de atuação efetiva daquele organismo.

O cenário das práticas de tradução no interior da Unasul pode ter sua origem nas diversas circunstâncias observadas empiricamente e alegadas por seus funcionários (como a restrição orçamentária). No entanto, este cenário existe como tal, é um dado de realidade e, por isso, numa perspectiva crítica, deve ser analisado como uma política linguística, mesmo que não explicitada. Conforme postulamos na introdução, toda atividade de linguagem é também uma atividade política, e as práticas de tradução 
no seio de um organismo internacional configuram, inevitavelmente, uma política linguística. A escolha dos idiomas de trabalho (castelhano e inglês), em detrimento do português (apesar da importância do Brasil na geopolítica da região); a alegação de que o inglês permite uma abertura da instituição à comunidade internacional e a suposta necessidade dessa abertura; a negligência com relação à própria necessidade de tradução dos principais documentos; a disparidade entre status e corpus das línguas oficiais; a visível atitude leniente da parte dos representantes brasileiros com relação à não necessidade de uso do português sob a justificativa de que o uso do castelhano dispensaria aquela língua - todos esses fatos, considerados em sua globalidade, constroem uma realidade em que as circunstâncias deixam de se apresentar como contingências ou eventualidades fortuitas e se configuram como opções políticas ou, mais precisamente, glotopoliticas, para empregar o termo proposto por Guespin e Marcellesi (1986), que o empregam para designar "as diversas abordagens que uma sociedade faz da ação sobre a linguagem, tenha ela ou não consciência disso [...]", um termo "necessário para englobar todos os fatos de linguagem em que a ação da sociedade reveste a forma do político" (p.5). O tratamento dispensado na Unasul às línguas e à tradução, mesmo que se "tenha ou não consciência disso", evidenciam uma glotopolítica, cujas ações e consequências esperamos ter evidenciado neste trabalho.

\section{REFERÊNCIAS BIBLIOGRÁFICAS}

ARNOUX, E. N. (2008). La agenda Glotopolítica contemporánea. Hacia la integración sudamericana. In: ARNOUX, E. N.; BEIN, R. (org.), La regulación política de las prácticas linguiísticas. Buenos Aires: Eudeba, pp.1-15.

ARNOUX, E. N, DEL VALLE, J. (2010). Las representaciones ideológicas del lenguaje: Discurso glotopolítico y panhispanismo. Spanish in Context. v. 7, $n^{\circ}$ 1. pp.1-24.

ARNOUX, E. N; NOTHSTEIN, S. (2014). Introducción. Glotopolítica, integración regional sudamericana y panhispanismo. In: ARNOUX, E. N, NOTHSTEIN, S. (org.), Temas de Glotopolítica: integración regional sudamericana y panbispanismo. Buenos Aires: Biblos, pp.9-29.

BAGNO, M. (2011). O que é uma língua? Imaginário, ciência \& hipóstase. In: LAGARES, X.; BAGNO, M. (orgs.), Políticas da norma e conflitos linguísticos. São Paulo: Parábola, pp.355-387. 
CALVET, L.J. (2007). As políticas linguísticas, trad. Isabel de Oliveira Duarte, Jonas Tenfen e Marcos Bagno. São Paulo: Parábola Editorial, 2007.

DINIZ, L. R. A. (2016). A promoção do português no espaço de enunciação do Mercosul: alguns equívocos históricos estruturantes. In: ARNOUX, E. N; LAURIA, D. (org.), Lenguas y discursos en la construcción de la ciudadanía sudamericana. Gonnet: UNIPE: Editorial Universitaria, pp.99-113.

EC (EUROPEAN COMISSION). (2015). Translation and the European Union. Disponível em < http://ec.europa.eu/dgs/translation/translating/index_en.htm>. Acesso em 23 jun. 2015.

FISCHER, M. (2010). Language (policy), translation and terminology in the European Union. In: THELEN, M.; STEURS, F. (org.), Terminology in everyday life. Amsterdã: John Benjamins, pp.21-34.

FOUCAULT, M. (1987) A arqueologia do saber, trad. Luiz Felipe Baeta Neves. Rio de Janeiro: Forense-Universitária, 1987, $3^{\mathrm{a}}$ edição.

GUESPIN, L.; MARCELLESI, J.-B. (1986). Pour la glottopolitique. Langages, n. 83, pp.534.

KOWERT, P. (1998). Agent versus Structure in the Construction of National Identity. In: KUBÁLKOVÁ, V.; ONUF, N.; KOWERT, P. (org.), International Relations in a Constructed World. Londres: Routledge, 1998, pp.101-122.

LINK, D. (2016). Volvernos calibanes: del panamericanismo al Mercosur. In: ARNOUX, ARNOUX, E. N; LAURIA, D. (org.), Lenguas y discursos en la construcción de la ciudadanía sudamericana. Gonnet: UNIPE: Editorial Universitaria, pp.185-191.

MARCUSCHI, L. A. (2008). Produção textual, análise de gêneros e compreensão. São Paulo: Parábola, 2008.

MOSSOP, B. (1988). Translating institutions: a missing factor in translation theory. TTR: traduction, terminologie, rédaction, vol. 1, $\mathrm{n}^{\mathrm{o}} 2, \mathrm{pp} .65-71$.

NU (NACIONES UNIDAS). (2014). UNASUR: Un espacio de cooperación e integración para el desarrollo. Santiago, Naciones Unidas, 2014. Disponível em: < http://www. unasursg.org/es/la-region-en-cifras >. Acesso 10 jun. 2016. 
SCHÄFFNER, C.; TCACIUC, L. S.; TESSEUR, W. (2014). Translations practices in political institutions: a comparison of national, supranational, and non-governmental organisations. Perspectives: Studies in Translatology, vol. 22, nº 4, pp.493-510.

TOURY, G. (1995). Descriptive Translation Studies and Beyond. Amsterdã: John Benjamins, 1995.

UNASUL. (2008). Tratado Constitutivo. In: GARCIA, E. V., Diplomacia Brasileira e Política Externa: documentos bistóricos (1493-2008). Rio de Janeiro: Contraponto, pp.731-744.

UNASUR. (2012). Reglamento General de UNASUR. Bogotá: UNASUR, 2012.

UNASUR. (2015). UNASUR/CMRE/Resolution $n^{\circ}$ 018/2015: Annual Budget of UNASUR for the year 2016. Disponível em < http://www.itamaraty.gov.br/images/ ed_integracao/docs_UNASUL/RES.018-2015ENG.pdf>. Acesso 20 dez. 2016.

van SPLUNDER, F. T. (2015). Taalstrijd:over relaties tussen talen in de wereld, Europa, Nederland en Vlaanderen. Bruxelas: ASP, 2015.

VIEIRA, R. (2010). Foucault em casa: aspectos discursivos da construção da Comunidade Sul-Americana de Nações (2004 - 2006). Brasília: Fundação Alexandre de Gusmão, 2010.

Recebido: 04/02/2018

Aceito: 20/02/2018 